\title{
Oxygen dynamics and transport in the Mediterranean sponge Aplysina aerophoba
}

\author{
Friederike Hoffmann · Hans Røy $\cdot$ Kristina Bayer • \\ Ute Hentschel · Martin Pfannkuchen · \\ Franz Brümmer $\cdot$ Dirk de Beer
}

Received: 31 January 2007 / Accepted: 3 January 2008/Published online: 22 January 2008

(C) Springer-Verlag 2008

\begin{abstract}
The Mediterranean sponge Aplysina aerophoba kept in aquaria or cultivation tanks can stop pumping for several hours or even days. To investigate changes in the chemical microenvironments, we measured oxygen profiles over the surface and into the tissue of pumping and nonpumping A. aerophoba specimens with Clark-type oxygen microelectrodes (tip diameters $18-30 \mu \mathrm{m}$ ). Total oxygen consumption rates of whole sponges were measured in closed chambers. These rates were used to back-calculate the oxygen distribution in a finite-element model. Combining direct measurements with calculations of diffusive flux and modeling revealed that the tissue of non-pumping sponges turns anoxic within $15 \mathrm{~min}$, with the exception of a $1 \mathrm{~mm}$ surface layer where oxygen intrudes due to molecular diffusion over the sponge surface. Molecular diffusion is the only transport mechanism for oxygen into non-pumping sponges, which allows total oxygen
\end{abstract}

Communicated by M. Wahl.

F. Hoffmann $(\bowtie) \cdot H$. Røy $\cdot$ D. de Beer

Max Planck Institute for Marine Microbiology,

Celsiusstr. 1, 28359 Bremen, Germany

e-mail: fhoffman@mpi-bremen.de

K. Bayer - U. Hentschel

Research Center for Infectious Diseases,

University of Würzburg, 97070 Würzburg, Germany

M. Pfannkuchen · F. Brümmer

Biologisches Institut, Abteilung Zoologie, Universitaet Stuttgart, Pfaffenwaldring 57, 70569 Stuttgart, Germany

Present Address:

H. Røy

Center for Geomicrobiology, Department of Biological Sciences, University of Århus, Ny Munkegade 1540,

0800 Århus C, Denmark consumption rates of $6-12 \mu \mathrm{mol} \mathrm{cm} \mathrm{cm}^{-3}$ sponge day ${ }^{-1}$. Sponges of different sizes had similar diffusional uptake rates, which is explained by their similar surface/volume ratios. In pumping sponges, oxygen consumption rates

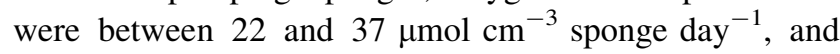
the entire tissue was oxygenated. Combining different approaches of direct oxygen measurement in living sponges with a dynamic model, we can show that tissue anoxia is a direct function of the pumping behavior. The spongemicrobe system of A. aerophoba thus has the possibility to switch actively between aerobic and anaerobic metabolism by stopping the water flow for more than $15 \mathrm{~min}$. These periods of anoxia will greatly influence physiological variety and activity of the sponge microbes. Detailed knowledge about the varying chemical microenvironments in sponges will help to develop protocols to cultivate sponge-associated microbial lineages and improve our understanding of the sponge-microbe-system.

\section{Introduction}

Sponges are sedentary filter-feeding organisms, characterized by a simple body plan built around a system of water canals and cavities. Flagellated cells in the choanocyte chambers produce a water current, providing the sponge body with nutrients and oxygen. The species Aplysina aerophoba Nardo 1843 is abundant in the MediterraneanAtlantic and occurs at light-exposed sites at depths from 5 to $15 \mathrm{~m}$. Aplysina sponges consist of numerous upright tubes that are fused at the base (Fig. 1a). The water path enters the sponge body through the pores at the sponge surface, leads through the canal system of the sponge body to the central atrium, and finally to the opening at the top of 
the tubes (osculum), as seen in Fig. 1b. A. aerophoba, as many demosponges, hosts high amounts of associated microbes (Hentschel et al. 2002). Most of these microbes are localized extracellularly in the mesohyl matrix where they contribute up to $38 \%$ of the sponge biomass (Vacelet 1975). The microbial community of A. aerophoba is
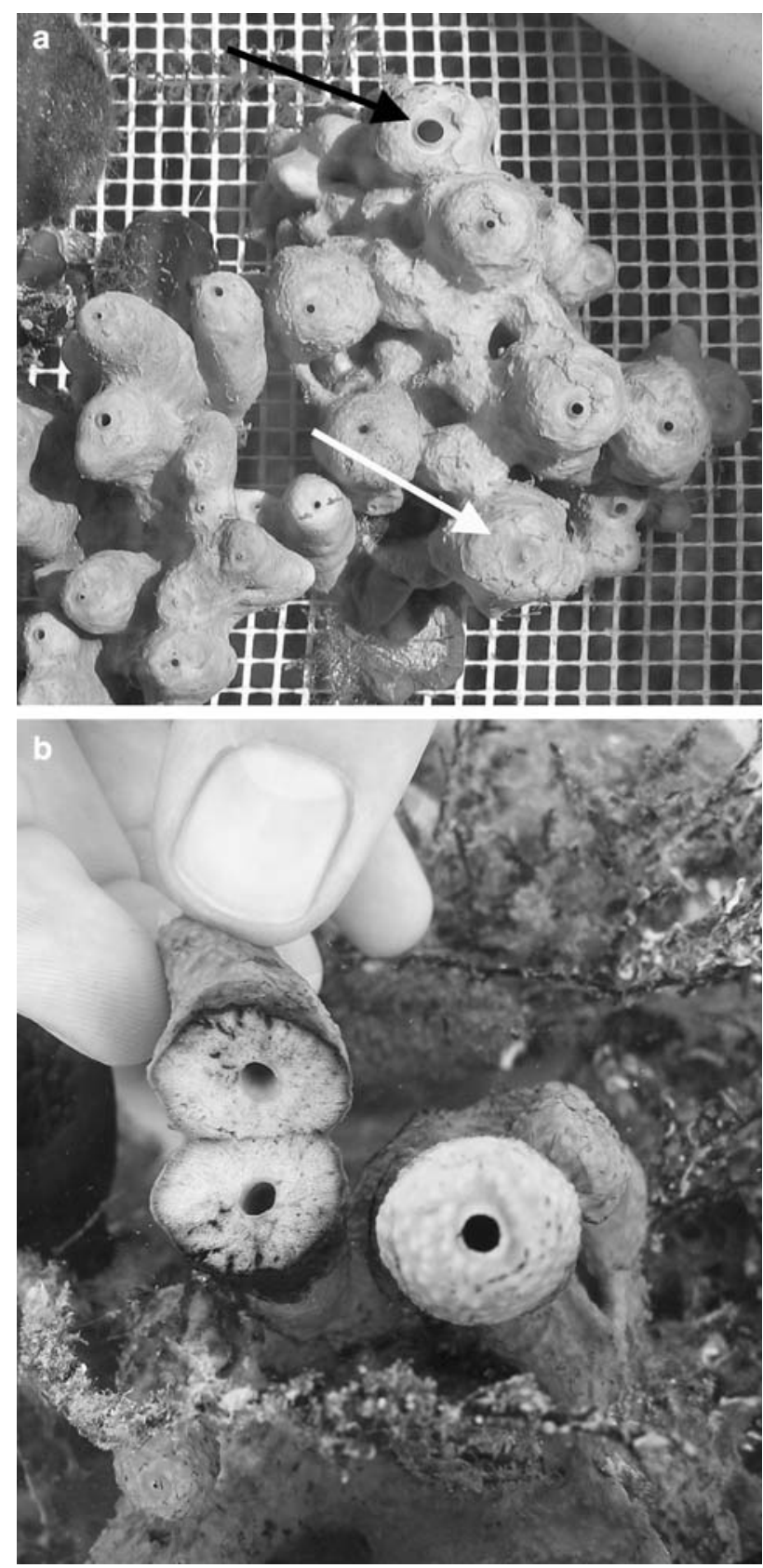

Fig. 1 Aplysina aerophoba. a A large specimen in a cultivation tank with several chimney-like oscules. Actively pumping oscules (black arrow) appear open, while non-pumping oscules (white arrow) appear closed. b Path of the water through the canal system of A. aerophoba visualized with non-particulate water soluble ink which was applied at the sponge surface. Water is pumped from the pores at the sponge surface through the canals in the tissue and finally enters the atrium in the center of the sponge, from where it is expelled through the oscule species-specific and surprisingly resistant to perturbations, such as starvation, exposure to antibiotics and transplantation to different habitats (Friedrich et al. 2001; Thoms et al. 2003).

Many sponges reduce or even stop their in situ pumping activity for several hours at irregular intervals (Reiswig 1971; Vogel 1977; Pile et al. 1997). Oxygen microsensors provide a powerful tool to investigate microscale oxygen distribution; this technique has only recently found its application on sponges (Schönberg et al. 2004). Hoffmann et al. (2005b) described a possible correlation between pumping activity and oxygen concentrations in sponge tissue: tissue anoxia was found in both weakly pumping and non-pumping G. barretti, but was more pronounced in non-pumping situations. Sulfate reduction, an anaerobic microbial process, was found to take place in the tissue of this species, proving the activity of anaerobic microbes in the sponge mesohyl. Also, other anaerobic processes could occur during periods of anoxia, like denitrification and fermentation (Taylor et al. 2007).

Gatti et al. (2002) described the reduced oxygen conditions they found in Suberites domuncula to be dependent on the surrounding flow regime, as well as on culturing conditions of the sponge.

Is there a direct relationship between sponge pumping activity and tissue oxygen, and can we thus conclude from sponge pumping behavior its expected tissue oxygen concentration? We investigated the oxygen dynamics in A. aerophoba combining direct oxygen measurements and dynamic modeling.

\section{Methods}

Sampling and maintenance of sponges

Sponges were sampled in the Adriatic Sea in the Limski kanal close to Rovinj, Croatia $\left(45^{\circ} 8^{\prime} \mathrm{N}, 13^{\circ} 37^{\prime}\right.$ E) between 5 and $15 \mathrm{~m}$ water depth by SCUBA diving following the CMAS (World Underwater Federation) rules for scientific diving. Within $2 \mathrm{~h}$ after collection, the sponges were transferred to cultivation tanks with running seawater at in situ temperature $\left(18^{\circ} \mathrm{C}\right)$ and $35 \%$ salinity at the Center for Marine Research of the Ruder Boskovic Institute. Experiments were carried out within 1-3 days after sampling.

Calculation of sponge volume and surface area

Sponge volume was measured by water volume displacement: small sponges were placed directly in a graduated beaker (10 ml-scale) half filled with sea water. Larger specimens were placed in a beaker which was filled to the 
top. The sponge was carefully placed in the beaker, removed again, and the displaced water was added from a graduated beaker. The sponge surface area was calculated from height and diameter assuming a cylindrical geometry. To assess the accuracy of this assumption, the volume calculated from the cylindrical model was compared to that obtained by volume displacement. The divergences were $17-27 \%$.

Measurements of oxygen consumption and distribution

Oxygen consumption of whole sponge specimens were measured with Clark-type microelectrodes (Clark et al. 1953; Revsbech 1989) by incubating sponges of known volume in gas-tight chambers. Tip diameters of the sensors were $18-30 \mu \mathrm{m}$, the $90 \%$ response time was about $1 \mathrm{~s}$ and the stirring-sensitivity less then $1 \%$. Pumping activity of the sponges was monitored during incubations by observing the oscules, which appeared open in a pumping individual and closed in a non-pumping sponge (Fig. 1a).

Oxygen profiles with $100 \mu \mathrm{m}$ steps were measured across the outer surface of $A$. aerophoba as described by Schönberg et al. (2004) using the microelectrodes described above. Eighteen profiles in total were taken from five sponge individuals, six during high pumping, nine during no pumping and three during weak pumping activity. Profiles which were taken at weak or intermediate pumping activity were not used for calculations. Profiles were taken on the "chimney"-part of the sponge, $0.5-4 \mathrm{~cm}$ from the oscule. Oxygen uptake via molecular diffusion during nonpumping was calculated from the profiles according to Fick's first law (Jørgensen and Revsbech 1985; Rasmussen and Jørgensen 1992)

flux $=-D \mathrm{~d} C / \mathrm{d} x$.

where $\mathrm{d} C / \mathrm{d} x$ is the concentration gradient in the diffusive boundary layer (DBL) and $D$ the diffusion coefficient for $\mathrm{O}_{2}$ calculated for a given temperature and salinity according to Li and Gregory (1974).

The calculated oxygen uptake rates per area were divided by the oxygen penetration-depth to convert them to volumetric rates, and multiplied with the sponge surfacearea to obtain total respiration rates. The correlation between pumping activity and oscula-aperture could be confirmed during profile measuring by visualizing the water current from the oscule with fluoresceine dye or small particles (see also Fig. 1a).

Penetration deeper than $1 \mathrm{~mm}$ was not possible without pre-piercing with a needle. Profiles measured in these holes were disturbed and therefore not used for flux calculations or for inferring the concentrations in the undisturbed tissue. Once inserted stationary in the tissue, however, a third independent rate of volumetric oxygen consumption could be calculated directly as the rate of concentration change over time after a sponge stopped pumping. This approach is valid as long as diffusion into the volume sensed by the microsensor is in steady state with diffusion out of the volume, i.e., until the profile develops curvature. For the central parts of the sponge tissue this does not happen before after several minutes.

\section{Modeling of oxygen distribution}

The measured volumetric oxygen consumption rates were used to back-calculate the oxygen distribution in the sponge. The model calculation was performed in Comsol Multiphysics, which can perform reaction-diffusionadvection calculations in an arbitrary geometry by dividing it into triangular finite elements. Geometry and calculation mesh is defined by the user and the time discretization handled automatically to assure numerical stability. The applied model describes a single $15 \mu \mathrm{m}$ wide pore with $30 \mu \mathrm{m}$ surrounding tissue in radial symmetry (Fig. 5). The modeled domain reaches from the outer surface of the sponge to the center of the atrium. A DBL is included on both the inner and outer surface. The rationale behind the representation is that a $50 \mathrm{~cm}^{3}$ sponge would consist of $\sim 500,000$ such sections. The boundary conditions were $280 \mu \mathrm{M}$ oxygen at the outer boundary of the outer DBL, radial symmetry around the center of the pore (left vertical axis in Fig. 5) and no flux across the right boundary in Fig. 5. Flow was imposed as a homogeneous radial velocity through the pore. Modeled flow in the pore was varied from zero to well above the realistic range of volumetric filtration rates for sponges $\left(2-12 \mathrm{~mL}\right.$ water $\mathrm{cm}^{-3}$ sponge $\min ^{-1}$; Reiswig 1974, 1981; Pile et al. 1997). At flow velocities in the pore above zero the atrium water was not included in the model. Under these conditions the boundary between atrium and tissue was modeled as a "neutral" outflow with no influence on the flow in the pore. Molecular diffusion was active in all domains at all times. Because oxygen diffuses freely through the cytoplasm of the sponge cells we used the diffusion coefficient for seawater at $18^{\circ} \mathrm{C}$ and $35 \%$ o $\left(1.7 \times 10^{-9} \mathrm{~m}^{-2} \mathrm{~s}^{-1}\right)$ throughout the model. Oxygen was consumed according to Michaelis Menten kinetics. In addition to the biological relevance, the numerical solution according to Michaelis Menten kinetics have the advantage of being numerically stable close to zero concentration where abstract simplifications often fail. Given that the oxygen concentration through most of the sponge will be either zero or much larger than $K_{\mathrm{m}}$, the actual value chosen is not critical for mass transfer considerations. $K_{\mathrm{m}}$ was set to $1 \mu \mathrm{mol} \mathrm{L}{ }^{-1}$, and $V_{\max }$ was based on the measured oxygen consumption rate $\left(30 \mu \mathrm{mol} \mathrm{cm} \mathrm{cm}^{-3}\right.$ sponge day ${ }^{-1}$ ) at saturating oxygen concentrations. 


\section{Results}

Oxygen consumption from respiration chambers

Respiration rates of four different sponge specimens are shown in Table 2. Rates of non-pumping sponges were between 6.46 and $8.94 \mu \mathrm{mol} \mathrm{O}_{2} \mathrm{~cm}^{-3}$ sponge day ${ }^{-1}$, while rates of constantly pumping sponges ranged between 22.98 and $30.69 \mu \mathrm{mol} \mathrm{O} \mathrm{Cm}^{-3}$ sponge day ${ }^{-1}$. Sponge 1 resumed pumping in the respiration chamber twice after a nonpumping period, which resulted in a continuous increase of respiration rates. Notably, the final rates were higher than respiration rates of constantly pumping sponges and reached up to $37.5 \mu \mathrm{mol} \mathrm{O} \mathrm{Cm}^{-3}$ sponge day ${ }^{-1}$. Figure 2 shows detailed respiration rates of sponge 1 in relation to pumping and non-pumping periods. A continuous increase of oxygen consumption was observed when the sponge resumed pumping after a non-pumping period. The difference between the rate of a constantly pumping individual and the maximum rates were 5-7 $\mu \mathrm{mol} \mathrm{cm} \mathrm{cm}^{-3} \mathrm{day}^{-1}$.

Oxygen profiles across the sponge surface

The oxygen concentration in the water column was stable at $280 \mu \mathrm{M}$. An oxygen electrode introduced through the osculum and $10 \mathrm{~mm}$ into the pre-oscular cavity (=atrium) of A. aerophoba specimens showed $\mathrm{O}_{2}$ concentrations between 67 and $186 \mu \mathrm{M}$ in pumping sponges. The oxygen concentrations in the atrium varied over time but not with depth, thus the atrium was well mixed during pumping.

Long-term measurements where the electrode was left in the sponge tissue for several hours showed that there was never a direct response on the insertion of the electrode, while changes in oxygen concentration over time were observed frequently, often several hours after the insertion

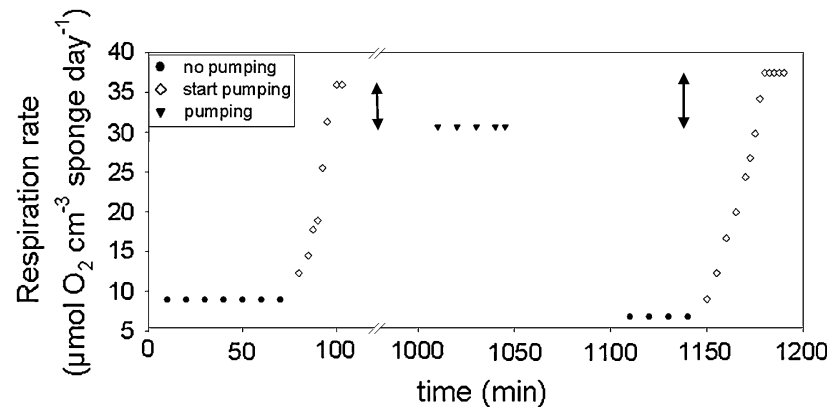

Fig. 2 Respiration rates as calculated from oxygen concentration changes in respiration chambers. Rates of sponge 1 over a time course with pumping and non-pumping periods are shown. When the sponge starts pumping after a non-pumping period, rates are continuously increasing and finally reach a maximum value which is $5-7 \mu \mathrm{mol}$ $\mathrm{cm}^{-3}$ day $^{-1}(20 \%)$ higher compared to respiration when pumping constantly

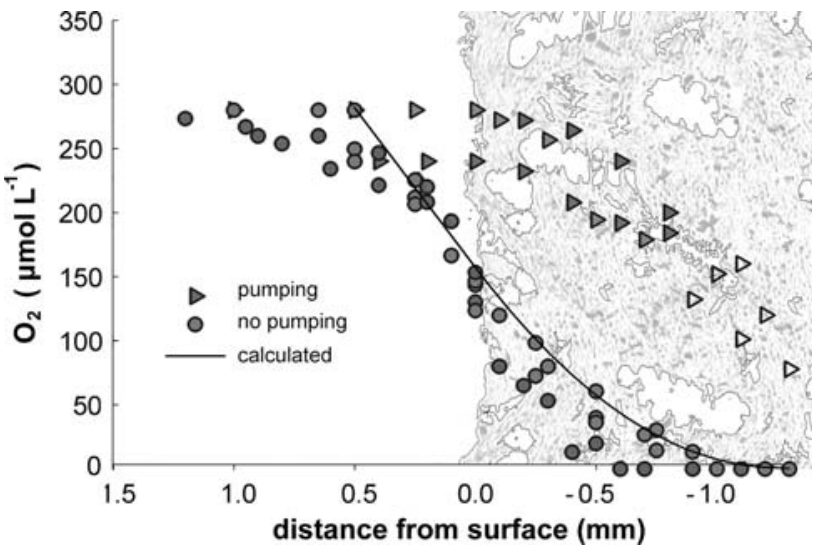

Fig. 3 Oxygen profiles of pumping and non-pumping A. aerophoba across the outer surface of the sponge. The tissue is indicated by a drawing based on an image of a thin section at the appropriate scale. Profiles of non-pumping sponges show a parabolic shape with a diffusive boundary layer above the surface, and oxygen depletion below $1 \mathrm{~mm}$ of tissue. Measured profiles of non-pumping sponges show excellent agreement with concentrations predicted by model calculation (straight line). Profiles of pumping sponges show higher oxygen concentrations in the sponge tissue as well as at the surface

of the sensor. We therefore consider microelectrode measurements in sponge tissue as a non-intrusive tool to investigate sponge physiology.

Oxygen profiles in non-pumping sponges always showed a distinct DBL and parabolic decrease to zero 0.6$1 \mathrm{~mm}$ below the sponge surface. Typical profiles of pumping and non-pumping sponges are shown in Fig. 3. All oxygen consumption rates calculated according to Eq. 1 were very similar between two measured sponges: the diffusive oxygen flux across the sponge-water interface was $4.5 \mu \mathrm{mol} \mathrm{O} \mathrm{cm}^{-2} \mathrm{day}^{-1}$ for sponge 1 and $4.7 \mu \mathrm{mol}$ $\mathrm{O}_{2} \mathrm{~cm}^{-2}$ day $^{-1}$ for sponge 3 . The volumetric oxygen consumption rate in the oxygenated surface layer of nonpumping sponges, calculated by dividing the oxygen flux with the thickness of the oxic zone, was $48.54 \mu \mathrm{mol}$ $\mathrm{cm}^{-3}$ day $^{-1}$ for sponge 1 , and $50.79 \mu \mathrm{mol} \mathrm{cm}{ }^{-3}$ day $^{-1}$ for sponge 3 (Table 2). Assuming an even diffusive flux over the entire surface exposed to the water (compare Table 1), the total oxygen consumption of the sponges were $11.91 \mu \mathrm{mol} \mathrm{cm}{ }^{-3} \mathrm{day}^{-1}$ for sponge 1 , and $12.56 \mu \mathrm{mol}$

Table 1 Overview of sponge parameters

\begin{tabular}{llcl}
\hline & \multicolumn{2}{l}{ Sponge parameters } \\
\cline { 2 - 4 } & Volume $\left(\mathrm{cm}^{3}\right)$ & Surface $\left(\mathrm{cm}^{2}\right)$ & Surf/Vol ratio $\left(\mathrm{cm}^{-1}\right)$ \\
\hline Sponge 1 & 70 & 184.41 & 2.63 \\
Sponge 2 & 15 & 32.4 & 2.16 \\
Sponge 3 & 40 & 105.98 & 2.65 \\
Sponge 4 & 80 & & \\
\hline
\end{tabular}

Empty fields $=$ no data available 
Table 2 Comparison of respiration rates $\left(\mu \mathrm{mol} \mathrm{O}_{2} \mathrm{~cm}^{-3}\right.$ sponge day ${ }^{-1}$ ) of four different sponge specimens in different physiological states, measured in closed chambers as well as calculated from diffusive oxygen profiles over the surface

\begin{tabular}{|c|c|c|c|c|c|c|}
\hline & \multicolumn{3}{|l|}{ No pumping } & \multicolumn{3}{|l|}{ Pumping } \\
\hline & $\begin{array}{l}\text { From chamber- } \\
\text { total sponge }\end{array}$ & $\begin{array}{l}\text { From surface } \\
\text { profiles- } \\
\text { total sponge }\end{array}$ & $\begin{array}{l}\text { From surface } \\
\text { profiles- } \\
\text { oxic layer }\end{array}$ & $\begin{array}{l}\text { From chamber- } \\
\text { constant } \\
\text { pumping }\end{array}$ & $\begin{array}{l}\text { From chamber- } \\
\text { start pumping }\end{array}$ & $\begin{array}{l}\text { From stationary } \\
\text { tissue electrode- } \\
\text { stop pumping }\end{array}$ \\
\hline Sponge 1 & $\begin{array}{l}7.88 \pm 1.5 \\
n=2\end{array}$ & 11.91 & 48.54 & 30.69 & $\begin{array}{l}36.74 \pm 1.1 \\
n=2\end{array}$ & 14.87 \\
\hline Sponge 2 & & & & $\begin{array}{l}29.7 \pm 0.3 \\
n=2\end{array}$ & & \\
\hline Sponge 3 & & 12.56 & 50.79 & 22.98 & & \\
\hline Sponge 4 & 6.46 & & & & & \\
\hline
\end{tabular}

Average values are given for repeated measurements. Empty fields $=$ no data available

$\mathrm{cm}^{-3}$ day $^{-1}$ for sponge 3 (Table 2 ). The $\mathrm{O}_{2}$ consumption rate calculated from the concentration change over time in

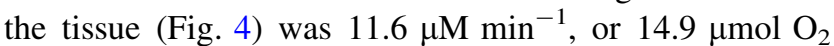
$\mathrm{cm}^{-3}$ sponge day ${ }^{-1}$. Oxygen profiles of pumping sponges (Fig. 3) reflect advective transport, with oxygen saturation at the sponge surface and linear concentration decrease within the tissue. Flux calculations from these profiles are not possible.

\section{Modeled oxygen dynamics}

Model calculations showed that the gradients between channels and surrounding tissue were insignificant relative

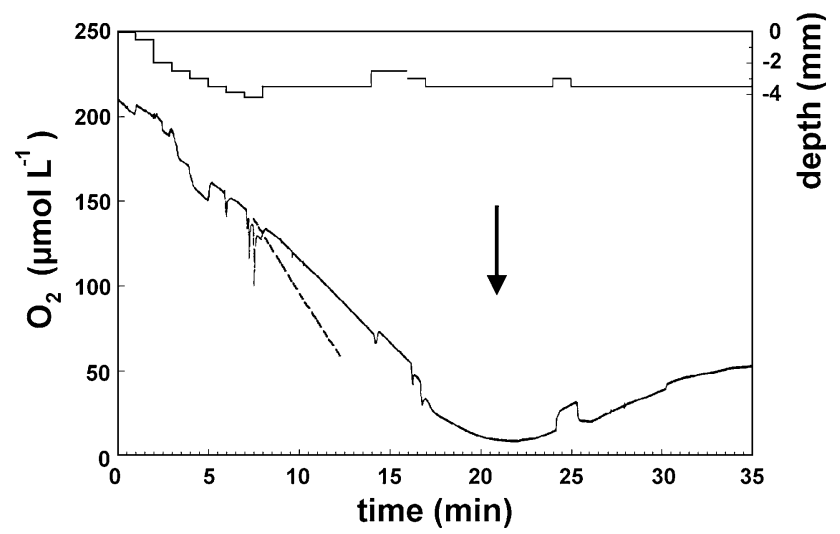

Fig. 4 Oxygen concentrations in a pre-pierced hole through the tissue and the pre-oscular cavity (atrium) over a time course of $35 \mathrm{~min}$. The microsensor's position in the tissue is indicated by the upper most line. Oxygen concentration decreased in a linear pattern at all depths when pumping stopped, leading to oxygen depletion in the tissue after $20 \mathrm{~min}$. Then the sponge started pumping again (arrow), resulting in rising oxygen concentrations inside the sponge. The modeled concentration decrease (dashed line) during non-pumping in $3.5 \mathrm{~mm}$ depth is indicated from 7.5 to $12 \mathrm{~min}$. The deviation between measured and modeled rate is likely due to the pre-piercing, and we hold the modeled results for the more reliable to the concentration gradient perpendicular to the sponge surface. Thus, the concentration in the canals was essentially the same as in the surrounding tissue at all pumping rates including non-pumping (Fig. 5).

During pumping, the $\mathrm{O}_{2}$ distribution in the sponge model was insensitive to the assumed concentration in the atrium because the atrium is down stream from the tissue. Figure 6 shows that a filtration rate lower than $0.1 \mathrm{ml}$ of water $\mathrm{cm}^{-3}$ sponge $\mathrm{min}^{-1}$, or a water residence time of more than $10 \mathrm{~min}$ in the sponge, would not be sufficient to balance sponge respiration, resulting in anoxia in the sponge tissue. At higher filtration rates, oxygen will be present in the sponge body and increase with increasing filtration rates, until it approaches saturation at a filtration rate of $2 \mathrm{ml}$ of water $\mathrm{cm}^{-3}$ sponge $\min ^{-1}$. The modeled transition in oxygen distributions upon switching off the pumping is presented in Fig. 7. The modeled concentration change over time is also shown in Fig. 4 together with a measured decrease. The modeled steady-state $\mathrm{O}_{2}$ distribution is also presented in Fig. 7. These calculations were fitted to the measured values in Fig. 3 .

\section{Discussion}

The oxygen distribution in non-pumping sponges is a balance between consumption and diffusive transport. This is confirmed by the excellent agreement between the modeled and measured steady state oxygen distribution in Fig. 3. Note that the modeled profile is based on the volumetric oxygen consumption rate measured by incubation in chambers. The modeled data in Fig. 3 are thereby independent from the measured data in the plot. The modeled temporal change (Fig. 7) can be compared to measured data by extracting the modeled concentration in a single point and compare it to the measurements from the stationary sensor in the sponge that had recently stopped 


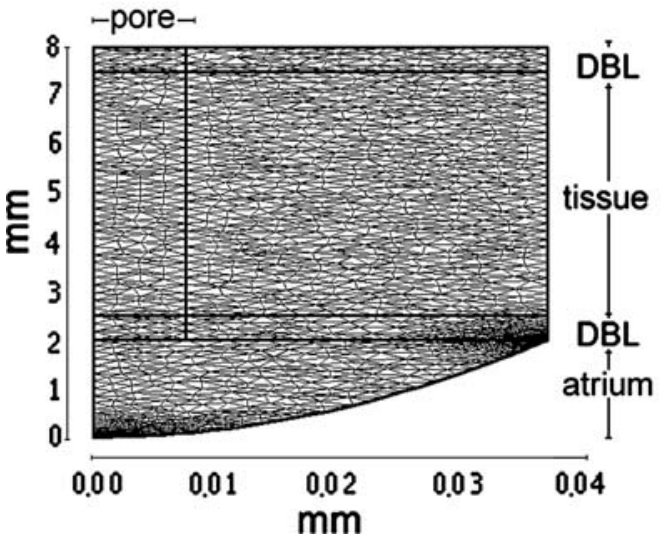

Fig. 5 Left: 2D view of a sponge section from the surface (top) to the central atrium through the diffusive boundary layer $(D B L)$ and the sponge tissue, with an idealized channel of $15 \mu \mathrm{m}$ diameter. Oxygen consumption takes place only in the tissue and advective transport is restricted to the pores. Molecular diffusion occurs throughout. The

pumping (Fig. 4). The oxygen concentration in the sponge decreases slower than expected from the model, and the volumetric rate of oxygen consumption falls about $50 \%$ below the estimates from microprofiles and chamber incubations. The low rate calculated from $\mathrm{d} C / \mathrm{d} t$ is probably caused by the pre-piercing and the rate is not used in further calculations. It does, however, independently confirm that the time scale it takes for the sponge to turn anoxic is in the order of $10-20 \mathrm{~min}$.

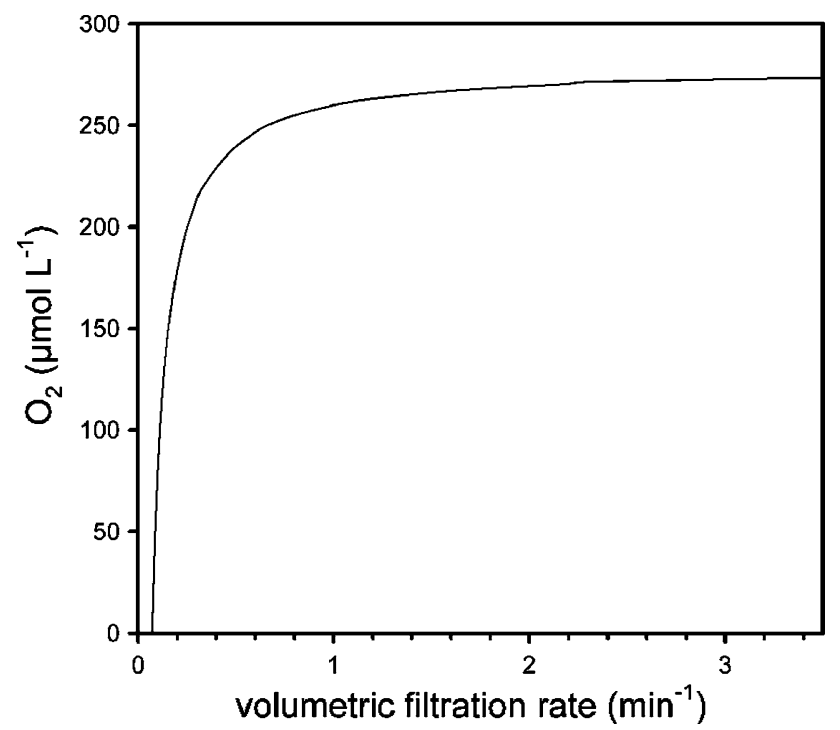

Fig. 6 Modeled oxygen concentration of the effluent water as function of sponge filtration rate. At filtration rates lower than $0.1 \mathrm{~mL}$ of water $\mathrm{cm}^{-3}$ sponge $\mathrm{min}^{-1}$, oxygen transport cannot keep up with sponge respiration, resulting in anoxia in the sponge tissue. At higher filtration rates, oxygen will be present throughout the sponge body and increase with increasing filtration rates, until it approaches saturation at a filtration rate of about $2 \mathrm{ml}$ of water $\mathrm{cm}^{-3}$ sponge $\mathrm{min}^{-1}$

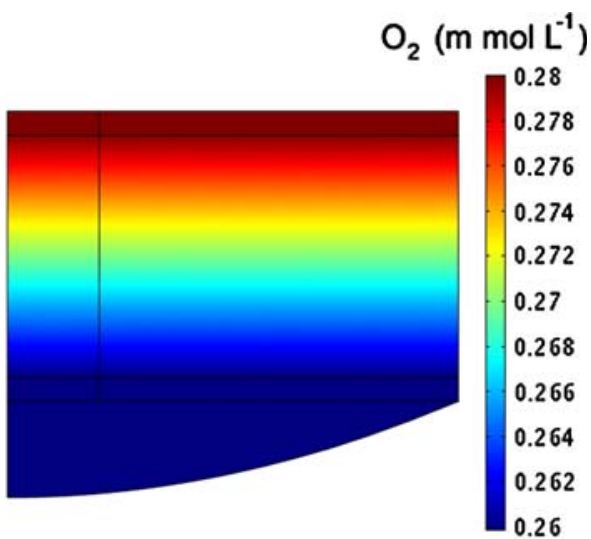

mesh represents the finite elements in the model. Right: modeled steady state oxygen distribution in a pumping sponge (velocity trough the pore $2 \mathrm{~mm} \mathrm{~s}^{-1}$, diffusion coefficient $1.7 \times 10^{-9} \mathrm{~m}^{2} \mathrm{~s}^{-1}, V_{\max }$ ( $\sim$ volumetric oxygen consumption rate) $3.5 \mathrm{E}-4 \mathrm{~mol} \mathrm{~m}^{-3} \mathrm{~s}^{-1}$ )

Non-pumping sponges typically show diffusive oxygen profiles over their surface and oxygen fluxes similar to those presented here were calculated (Hoffmann et al. 2005a; Schläppy et al. 2007). In contrast, microprofiles of actively pumping sponges show a domination of advective flux (Hoffmann et al. 2005b; Schläppy et al. 2007; Hoffmann et al. 2007). Our data presented here (Fig. 3) are consistent with these findings.

\section{Comparing oxygen consumption rates}

Respiration rates of non-pumping sponges calculated from diffusive profiles over the boundary layer are strikingly

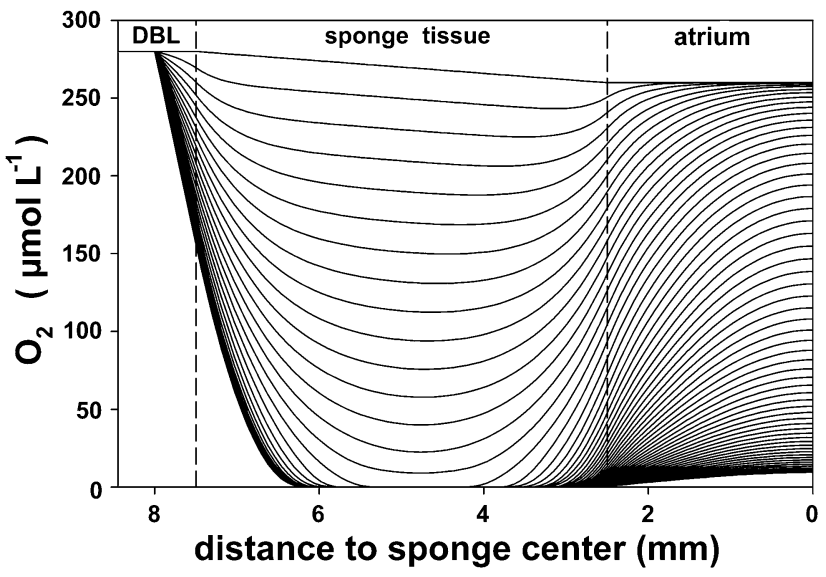

Fig. 7 Modeled evolution of oxygen distribution in A. aerophoba after pumping is stopped. The top line represents the steady-state pumping situation, each line below 1 min after pumping is stopped. According to this model, oxygen in the central tissue parts between sponge surface and atrium is depleted after $15 \mathrm{~min}$ of non-pumping. $D B L$ diffusive boundary layer 
similar to those measured in gas-tight chambers (Table 2). This is direct evidence that non-pumping sponges meet, in steady state, their oxygen needs by diffusion over their outer surface (exo-pinacoderm). This was already proposed by Hoffmann et al. (2005a), who calculated oxygen consumption from diffusive profiles over the surface of non-pumping explants of the cold-water sponge Geodia barretti. Total oxygen consumption $\left(9.07 \mu \mathrm{mol} \mathrm{cm}{ }^{-3}\right.$ day $\left.^{-1}\right)$ is comparable to both our directly measured and calculated rates of A. aerophoba $\left(6.46-12.56 \mu \mathrm{mol} \mathrm{cm}^{-3}\right.$ day $^{-1}$, Table 2). These rates are in the lower range of sponge respiration rates in general, which range between 5 and $600 \mu \mathrm{mol} \mathrm{O} \mathrm{Cm}^{-3}$ sponge day ${ }^{-1}$ (reviewed by Osinga et al. 1999). At times when molecular diffusion across the surface controls the $\mathrm{O}_{2}$ distribution and utilization, the surface/volume-ratio becomes a key parameter. Surface/ volume-ratios of our experimental sponges (Table 1) were between 2 and 3; regardless of sponge volume. This explains why non-pumping sponges of different sizes have similar oxygen consumption rates (Table 2). It is possible that A. aerophoba regulates its architecture to adapt to these transport phenomena.

When sponges resumed pumping after an inactive period, the initial respiration rates were approximately $20 \%$ higher than of constantly pumping individuals (Fig. 2). This might be due to re-oxidation of reduced compounds accumulated by anaerobic processes (fermentation or anaerobic microbial respiration) during the non-pumping period. Sulfate reduction and subsequent rapid sulfide reoxidation have already been shown in the sponge $G$. barretti (Hoffmann et al. 2005b). Recent detection of $16 \mathrm{~S}$ rRNA genes of the uncultured Nitrosospira subdivision of Betaproteobacteria (Bayer et al. 2007) and of Archaea (unpublished results) indicate that nitrification occurs in $A$. aerophoba. Nitrate produced by these microbes could principally fuel the anaerobic microbial process of denitrification, which is subject to our ongoing studies.

Volumetric respiration rates of the entire tissue, measured in constantly pumping sponges in gas-tight chambers, are close to the rates measured with microsensors in the oxygenated tissue parts of non-pumping sponges (Table 2). It is reasonable to assume that the surface layer should be slightly more reactive than the sponge tissue in general as the $\mathrm{O}_{2}$ consumption in the oxygenated surface layer might be enhanced by re-oxidation of reduced compounds produced in the anoxic tissue parts.

We do not have direct measurements of the in situ pumping rates of A. aerophoba. But according to Fig. 6 and the measured $\mathrm{O}_{2}$ concentration in the atrium, the volumetric filtration rate must have been between 0.5 and $1 \mathrm{~mL}$ water $\mathrm{cm}^{-3}$ sponge $\mathrm{min}^{-1}$ (or the residence time of water in the sponge must have been 1-2 min) during our experiments. Filtration rates of sponges in situ range between 2 and $12 \mathrm{~mL}$ water $\mathrm{cm}^{-3}$ sponge $\mathrm{min}^{-1}$ (Reiswig 1974, 1981; Pile et al. 1997). Such exchange rates would lead to excess $\mathrm{O}_{2}$ supply in A. aerophoba, and thereby tissue oxygen concentrations similar to the water column.

In conclusion, sponge tissue anoxia is a function of oxygen concentration in the water that passes through the sponge, the residence time of water in the sponge body, and sponge respiration rate. If the residence time is smaller than the oxygen content of the water divided by the sponge respiration rate, tissue parts which are not supplied by molecular oxygen diffusion over the surface become anoxic. This simplified relation would predict a critical residence time of $13 \mathrm{~min}$ for our sponge, A. aerophoba.

Oxygen dynamics in pumping and non-pumping A. aerophoba

Combining all observations, it can be concluded that the interior of A. aerophoba becomes anoxic within $15 \mathrm{~min}$ after pumping stops. After that, oxygen is only present in the outer-most $\mathrm{mm}$, supplied via diffusion trough the external surface. When the sponge re-starts pumping, the $\mathrm{O}_{2}$ concentration in the tissue becomes close to the watercolumn concentration within minutes and the entire sponge is supplied with oxygen in excess. Elevated oxygen consumption rates after non-pumping periods indicate anaerobic processes during non-pumping periods, resulting in the accumulation of reduced compounds which subsequently need to be oxidized. After this has happened, the oxygen consumption is homogeneous throughout the tissue. When A. aerophoba stops pumping for several hours or even days, as observed in aquaria and cultivation tanks, sponge cells and associated microbes must survive anoxic conditions.

While many sponge species reduce or even stop their in situ pumping activity for several hours at irregular intervals (Reiswig 1971; Vogel 1977; Pile et al. 1997), a recent field study on in situ pumping behavior of A. aerophoba did not show long periods of non-pumping unless disturbed mechanically (M. Pfannkuchen, unpublished data). Nevertheless, the sponge-microbe system of A. aerophoba has the potential to switch between aerobic and anaerobic metabolism. The closure of the osculum while A. aerophoba does not pump actively prevents the passive ventilation ("chimney effect") observed in other sponge genera (Vogel 1977). This could indicate that the tissue anoxia has a physiological function. The more common occurrence of non-pumping during cultivation than in situ might be a clue in understanding the problems of sponge cultivation, and in understanding the sponge and its microbes in general. Possible changes in the spongemicrobe-system due to a different pumping behavior 
should also be considered when sponges are cultured for biotechnological production of secondary metabolites.

Acknowledgments The team from Ruder Boskovic Intitute in Rovinj, Croatia, is kindly acknowledged for all forms of support during field work. We thank T. Winter and M. Voigt for assistance with diving, and A. Sigl and M. Wehrl for nice company in the field lab. This work would not have been possible without the superb microsensors prepared by the technicians of the microsensor group at MPI. F. H. is funded by the Deutsche Forschungsgemeinschaft (DFG, Project No. HO 3293/1-1), while U. H. (03F0414E) and F. B. acknowledge financial support by the excellence center Biotecmarin founded by the Federal Ministry of Education and Research $(\mathrm{BMB}+\mathrm{F})$. All the experiments complied with current German law.

\section{References}

Bayer K, Schmitt S, Hentschel U (2007) Microbial nitrification in Mediterranean sponges: possible involvement of ammoniumoxidizing Betaproteobacteria. In: Muricy G (ed) Porifera research: biodiversity, innovation, sustainability. Série Livros. Museu Nacional, Rio de Janeiro, pp 165-171

Clark LC, Wolf R, Granger D, Taylor A (1953) Continuous recording of blood oxygen tension by polarography. J Appl Physiol 6:189193

Friedrich AB, Fischer I, Proksch P, Hacker J, Hentschel U (2001) Temporal variation of the microbial community associated with the mediterranean sponge Aplysina aerophoba. FEMS Microbiol Ecol 38:105-113

Gatti S, Brey T, Müller WEG, Heilmayer O, Holst G (2002) Oxygen microoptodes: a new tool for oxygen measurements in aquatic animal ecology. Mar Biol 140:1075-1085

Hentschel U, Hopke J, Horn M, Friedrich AB, Wagner M, Hacker J, Moore BS (2002) Molecular evidence for a uniform microbial community in sponges from different oceans. Appl Environ Microbiol 68:4431-4440

Hoffmann F, Larsen O, Rapp HT, Osinga R (2005a) Oxygen dynamics in choanosomal sponge explants. Mar Biol Res $1: 160-163$

Hoffmann F, Larsen O, Thiel V, Rapp HT, Pape T, Michaelis W, Reitner J (2005b) An anaerobic world in sponges. Geomicrobiol J 22:1-10

Hoffmann F, Sauter E, Sachs O, Røy H, Klages M (2007) Oxygen distribution in Tentorium semisuberites and in its habitat in the
Arctic deep sea. In: Muricy G (ed) Porifera research: biodiversity, innovation, sustainability. Série Livros. Museu Nacional, Rio de Janeiro, pp 379-382

Jørgensen BB, Revsbech NP (1985) Diffusive boundary layers and the oxygen uptake of sediments and detritus. Limnology and Oceanography 30:111-122

Li YH, Gregory S (1974) Diffusion of Ions in sea-water and in deepsea sediments. Geochim Cosmochim Acta 38:703-714

Osinga R, Tramper J, Wijffels RH (1999) Cultivation of marine sponges. Mar Biotechnol 1:509-532

Pile AJ, Patterson MR, Savarese M, Chernykh VI, Fialkov VA (1997) Trophic effects of sponge feeding within Lake Baikal's littoral zone. 1. In situ pumping rate. Limnol Oceanogr 42:171-178

Rasmussen H, Jørgensen BB (1992) Microelectrode studies of seasonal oxygen uptake in a coastal sediment: role of molecular diffusion. Mar Ecol Prog Ser 81:289-303

Reiswig HM (1971) In situ pumping activities of tropical Demospongiae. Mar Biol 9:38-50

Reiswig HM (1974) Water transport, respiration and energetics of three tropical marine sponges. J Exp Mar Biol Ecol 14:231-249

Reiswig HM (1981) Partial carbon and energy budgets of the bacteriosponge Verongia fistularis (Porifera: Demospongiae) in Barbados. Mar Ecol Prog Ser 2:273-293

Revsbech NP (1989) An oxygen microsensor with a guard cathode. Limnol Oceanogr 34:472-276

Schläppy M-L, Hoffmann F, Røy H, Wijffels RH, Mendola D, Sidri M, Beer Dd (2007) Oxygen dynamics and flow patterns of Dysidea avara (Porifera, Demospongiae). J Mar Biol Assoc UK 86:1677-1682

Schönberg CHL, Hoffmann F, Gatti S (2004) Using microsensors to measure sponge physiology. Boll Mus Ist Biol Univ Genova 68:593-604

Taylor MW, Radax R, Steger D, Wagner M (2007) Sponge-associated microorganisms: evolution, ecology, and biotechnological potential. Microbiol Mol Biol Rev 71:259-347

Thoms C, Horn M, Wagner M, Hentschel U, Proksch P (2003) Monitoring microbial diversity and natural product profiles of the sponge Aplysina cavernicola following transplantation. Mar Biol 142:685-692

Vacelet J (1975) Étude en microscopiie électronique de l'association entre bactéries et spongiaires du genre Verongia (Dyctioceratida). J Micros Biol Cell 23:271-288

Vogel S (1977) Current-induced flow through living sponges in nature. Proc Natl Acad Sci USA 74:2069-2071 